\title{
Mechanisms of rockbolt support in jointed rock masses
}

\author{
T. Moyo University of the Witwatersrand, South Africa; and Xstrata Zinc, Australia
}

T.R. Stacey University of the Witwatersrand, South Africa

\begin{abstract}
Rockbolts are relied on as a key component of underground mining support systems, and have been the subject of ongoing research over several decades. However, in spite of their extensive use and the research, the interaction mechanisms between the rockbolt and the rock mass in jointed rock structures are still not fully understood. In addition, the actual work that rockbolts perform under stress, as well as the way they deform across joints, has not been completely captured nor explained.
\end{abstract}

In an attempt to improve the level of understanding relating to the reinforcement mechanisms of rockbolts in jointed rock masses, physical models of tunnels in simulated rock masses were constructed. The models represented a sedimentary rock mass with continuous bedding planes, and cross joints between the bedding. Different bedding dips were considered. 'Rockbolts' were installed to provide support to the tunnels. The models were subjected to lateral or vertical boundary deformations, or a combination of the two. Careful observations and photographic records of rockbolt behavioural mechanisms, as well as rock mass structural failure modes, were captured.

Instability in the model tunnels was a function of the bedding dip, increasing with an increase in the dip angle. Instability was greatest in models in which the bedding orientation was greater than $45^{\circ}$. In these models, rockbolts were effective as support only when block movement or rotation was restricted. However, the rockbolts were found to be very effective in supporting horizontally layered jointed structures.

Rockbolts were observed to attract loads due to rock mass movements. In resisting deformation, they were subjected to combinations of shear, bending, compressive and tensile loading. Rockbolt length and spacing were confirmed as important parameters in improving tunnel stability.

\section{$1 \quad$ Introduction}

Ground reinforcement includes, amongst other methods, the techniques of ground anchoring, cable bolting and rockbolting (Barley and Windsor, 2000). The aim of all ground reinforcement techniques is to ensure the stability of an artificial structure constructed within or on a soil or rock mass by the installation of structural elements within the ground.

Rockbolts have emerged over the years as an important support element in both underground and surface excavations. According to Grasselli (2004), rockbolting is the most effective and also the most economical means of supporting excavations in rock. During the last three decades, the use of rockbolts for underground rock reinforcement has been increasing steadily, and has become the primary support system in many underground mining operations (Peng and Tang, 1984; Jalalifar et al., 2006). Owing to their importance, rockbolts have received more research attention than any other form of ground control (Mark et al., 2001). Nevertheless, the actual work that they perform is yet to be reliably quantified. In conventional operations, in the recent history and to a certain extent in some present operations, the design of rock support systems tends to be based upon empirical rules generated from experience (Cording et al., 1971) and rock mass classification (for example, Barton et al., 1974; Barton, 2002). However, these approaches do not take into account the observed complexity of loading experienced by rockbolts in practice. The limit equilibrium and sophisticated numerical methods available nowadays, which allow for the incorporation of rockbolts in the analysis, are similarly not likely to be very reliable for jointed rock masses owing to the limitations of the behavioural assumptions in the analyses. Rock engineering design 
still relies on experimentation as more complex theories require more testing. According to Sakurai (2008), it is difficult to demonstrate the effectiveness of rockbolts using numerical analysis; hence, the necessity of conducting physical model tests still remains.

It is also worth noting that most failures of rock around underground openings are associated with joints, though these may be under rockbolt support. The complicated behaviour of jointed rock masses, and their interaction with rockbolts, are still largely unknown (Hoek et al., 2000). This indicates the relevance of further research into the behaviour of rockbolts in jointed rock masses. In this paper, the use of simple 2D physical models in the investigation of mechanisms of rockbolt support in jointed rock masses is described.

\section{$2 \quad$ Physical model testing}

With the increasing development of sophisticated numerical analysis tools for geotechnical engineering applications, the use of physical models has tended to lose favour. The incorporation of support elements into numerical analysis packages involves assumptions regarding their behaviour. For example, shotcrete is often modelled as a beam, and assumptions will be made regarding the behaviour of rockbolts - in tension, shear, anchorage, plate, etc. Such assumptions may be satisfactory for conservative designs, but, in cases of significant deformation, as often occurs in mining excavations, loading on rockbolts may be complex, involving multiple mechanisms, and designs based on the assumptions may thus be unreliable. Therefore, it is considered that there is still value to be had from physical modelling.

Consequently, in order to investigate mechanisms of rockbolt support as well as to observe the 'work' that rockbolts perform in jointed rock masses, simple 2D physical models were designed and constructed in the laboratory. The purpose of the models was demonstrative, rather than quantitative, and no attempt was made to achieve similitude conditions. Nevertheless, a semi-quantitative insight into the reinforcement mechanisms of rockbolted joints was obtained and the models managed to demonstrate realistic underground behaviours.

Rock mass models were hand-built using concrete bricks, whose sizes were cut to $100 \times 100 \times 50 \mathrm{~mm}$. Concrete bricks were used to simulate rock blocks as they were readily available which facilitated the building of the models. A sedimentary 'geological' structure, consisting of continuous bedding planes with cross joints between them, was simulated. Four different bedding orientations were used in the models, namely, horizontal $\left(0^{\circ}\right), 30^{\circ}, 45^{\circ}$ and $60^{\circ}$. The models were constructed within an outer steel frame $(1.5 \times 1.4 \mathrm{~m})$, which provided the reaction frame by means of which deformations could be applied to the models. An inner $0.6 \times 0.6 \mathrm{~m}$ steel tunnel frame was used as the formwork for the tunnels during the building of the models. The models are illustrated diagrammatically in Figures 1 and 2. 


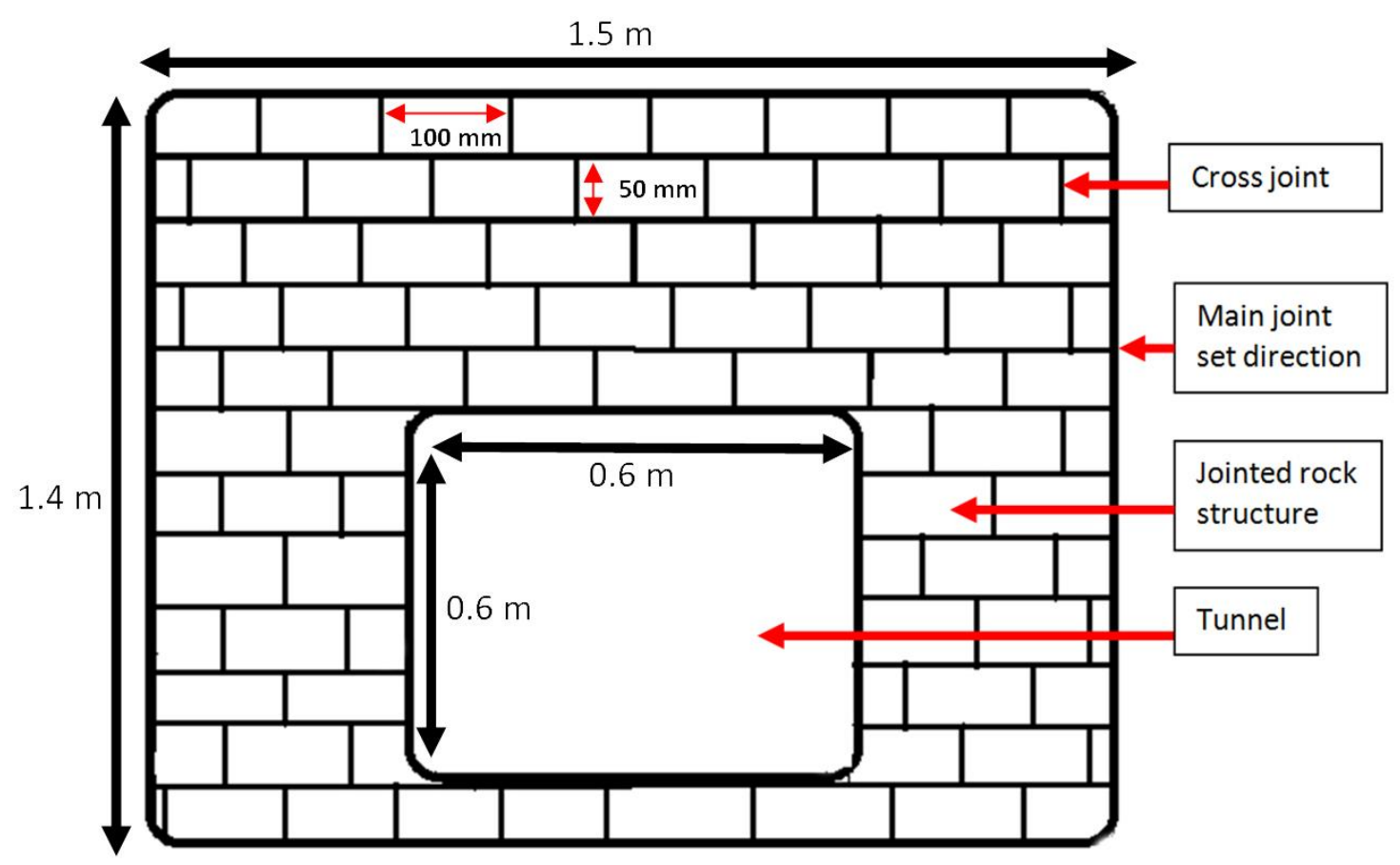

Figure 1 Schematic diagram for a structural orientation at $0^{\circ}$ to the horizontal

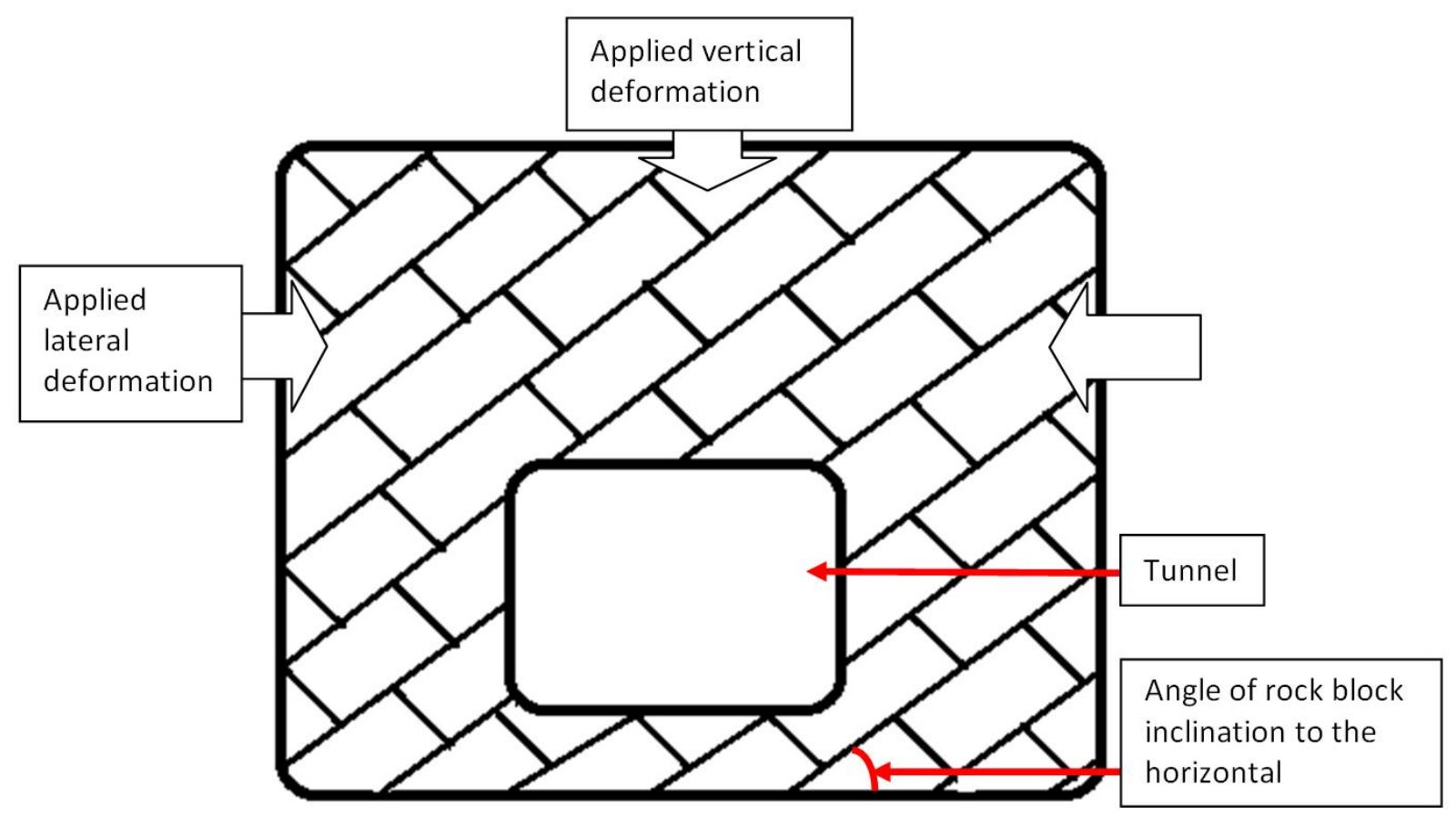

Figure 2 Schematic diagram for inclined structural orientations $\left(30^{\circ}, 45^{\circ}\right.$ and $\left.60^{\circ}\right)$

Rockbolts were simulated by $2.6 \mathrm{~mm}$ diameter mild steel wire. Several rockbolt lengths and spacings were investigated. The installation of these rockbolts was a simple process - in the required rockbolt locations, grooves were cut into the blocks to contain the wire. The rockbolts were installed in these grooves using epoxy adhesive, which simulated end anchoring and, in some cases, full column grouting. This simple 'external rockbolt' approach was chosen deliberately since the rockbolts would be clearly visible, and their behaviour could therefore be easily observed and recorded. Several rockbolt lengths were selected for the investigation. The spacing of the rockbolts was defined by their capacity in relation to the anticipated tributary area loading. For the purposes of this research, the empirical formula below (Farmer and Shelton, 1980), was employed for the standard testing pattern. This was adopted as it is applicable to competent, 
moderately jointed rock mass structures, and also gives consideration to the numbers of joint sets and their orientation relative to the excavation and rockbolt installations.

- $L=1 / 3$ tunnel span.

- $S=1 / 2 \mathrm{~L}$.

where $L$ is the bolt length and $S$ is the bolt spacing.

This therefore means that the standard pattern (control) for this particular project was as follows:

- Rockbolt length $=1 / 3(60)=20 \mathrm{~cm}$.

- Rockbolt spacing $=1 / 2(20)=10 \mathrm{~cm}$.

Once the rockbolts had been installed and the model was ready for testing, the inner steel frame was removed so that the tunnel would be free to respond to gravity and to deformations applied to the model boundaries. The models were subjected to differential deformations in the horizontal and vertical directions. These deformations were applied to steel plates on both vertical and horizontal boundaries of the model by means of bolts through the outer steel frame. No attempt was made to measure any loads applied, since it was the rockbolt deformations that were considered to be of greater importance. For each set-up, vertical, lateral and a combination of the two deformation schemes were used, while different rockbolt lengths and spacings were being investigated.

The following testing procedure was used for all the models:

- The steel frame was filled with bricks around the tunnel perimeter frame.

- Grooves for the steel wires were cut using a disc cutter. The steel wires were installed in the grooves, using epoxy adhesive, to simulate rockbolting.

- The tunnel perimeter frame was then removed to simulate tunnelling.

- Deformations were applied to the model boundaries using threaded steel bolts turned using a wrench. The applied deformations (vertical and horizontal) were distributed onto the bricks by means of reinforced steel plates.

- Deformation was observed and recorded using a digital camera.

- Deformation continued beyond the failure of the rock block specimen until the rock blocks interlocked to such an extent that further deformation of the model was inhibited from a practical point of view (limit of the applied deformation system capacity).

The photograph in Figure 3 below illustrates the various components of the models, while Figures 4 depicts a deformed tunnel, with the inner tunnel frame having been removed. The models allowed very easy observation of the actions of rockbolts when subjected to vertical and lateral deformations. The tunnel and rockbolt failure modes identified were based on visual and photographic observations at the time of failure, and the rockbolt response to the deformations was also photographically recorded. In this way a picture of the possible mechanisms of rockbolt behaviour could be created. 


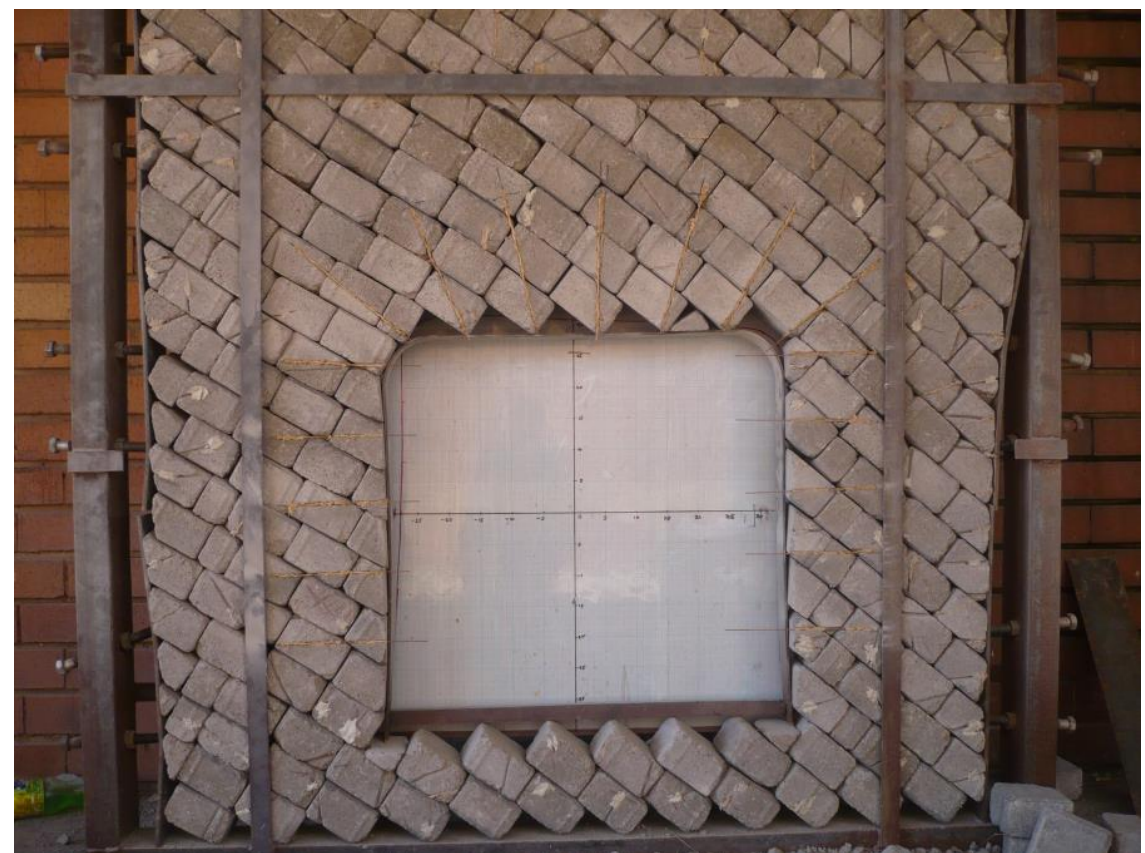

Figure 3 A constructed model with simulated grouted rockbolts before tunnel frame removal

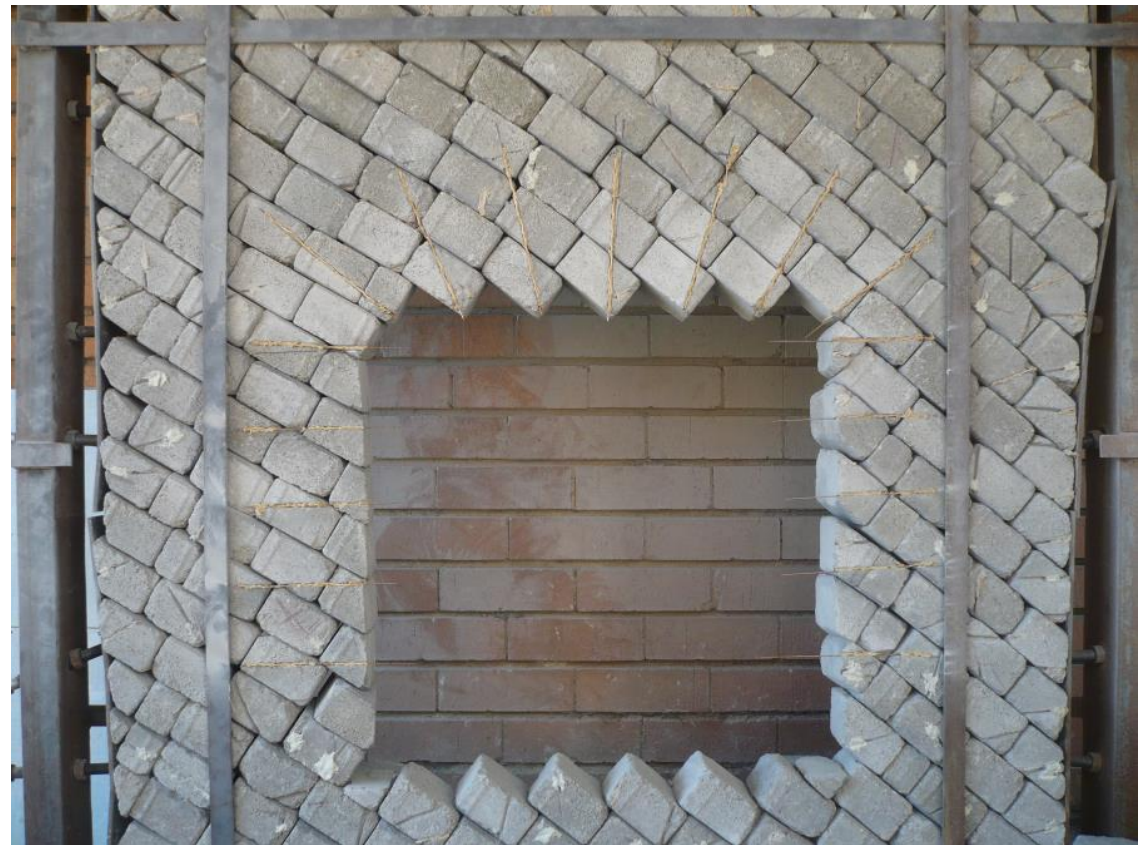

Figure 4 A deformed model, after the removal of the inner steel tunnel frame

\section{Results and discussion}

The results that are presented in this paper are based on four orientations of the main bedding 'geological' structures, which are, at $0^{\circ}, 30^{\circ}, 45^{\circ}$ and $60^{\circ}$ from the horizontal respectively. Firstly, the behaviour of the models during applied deformation is considered, and the analysis of the behaviour of the installed rockbolts then follows. 


\subsection{Behaviour of the model tunnels}

\subsubsection{Horizontally oriented structure}

In all the horizontal structures tested, it was observed that on removing the tunnel perimeter frame there was a sag in the tunnel roof under the rock's own weight, after which sections of the rock structure would become loose. This also resulted in the widening of the tunnel sides at the corners as illustrated in Figure 5.

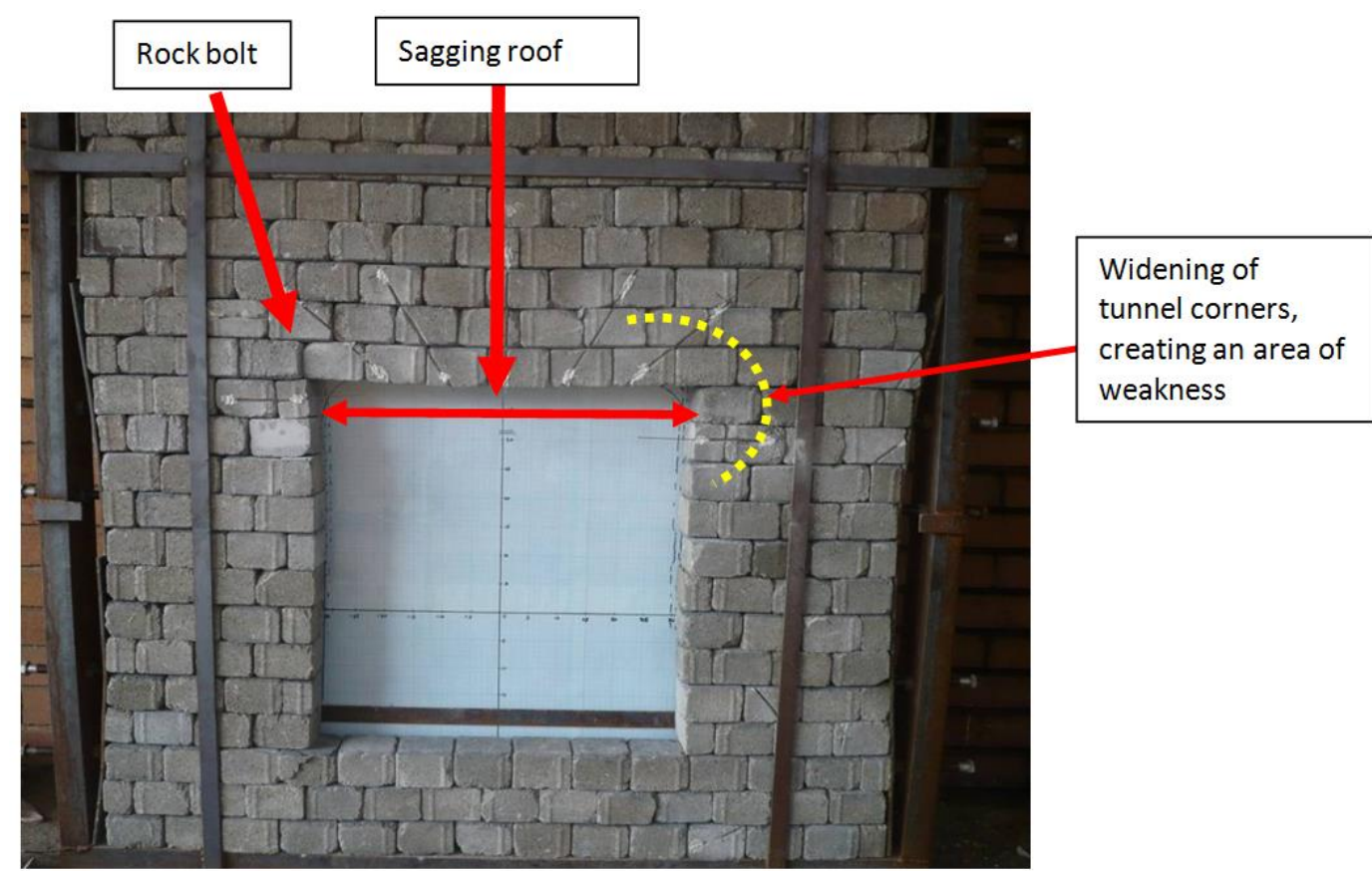

Figure 5 Loaded tunnel model after the removal of the tunnel frame

Deformation applied to the model resulted in the dilation of joints, primarily due to the movement of unsupported rock blocks. This movement across the joints resulted in the generation of shear and bending loads on the rockbolts, especially at the tunnel abutments and side walls. Rockbolts in the roof remained intact throughout the loading process, supporting the tunnel periphery. However, in the case of the grouted bolts, the grout (epoxy) was observed to crack at the top anchorage points. This implies that stress on the bolts was concentrated at these points.

\subsection{2 $30^{\circ}$ orientation}

In the models tested with a $30^{\circ}$ orientation to the horizontal, major side wall failures were observed. Rock blocks from the side walls tended to slide into the tunnel cavity. Rock block movement in the left side wall was mainly gravity induced, while in the right tunnel side, movement resulted from joint dilation in the main joint set direction, as illustrated in Figure 6. 


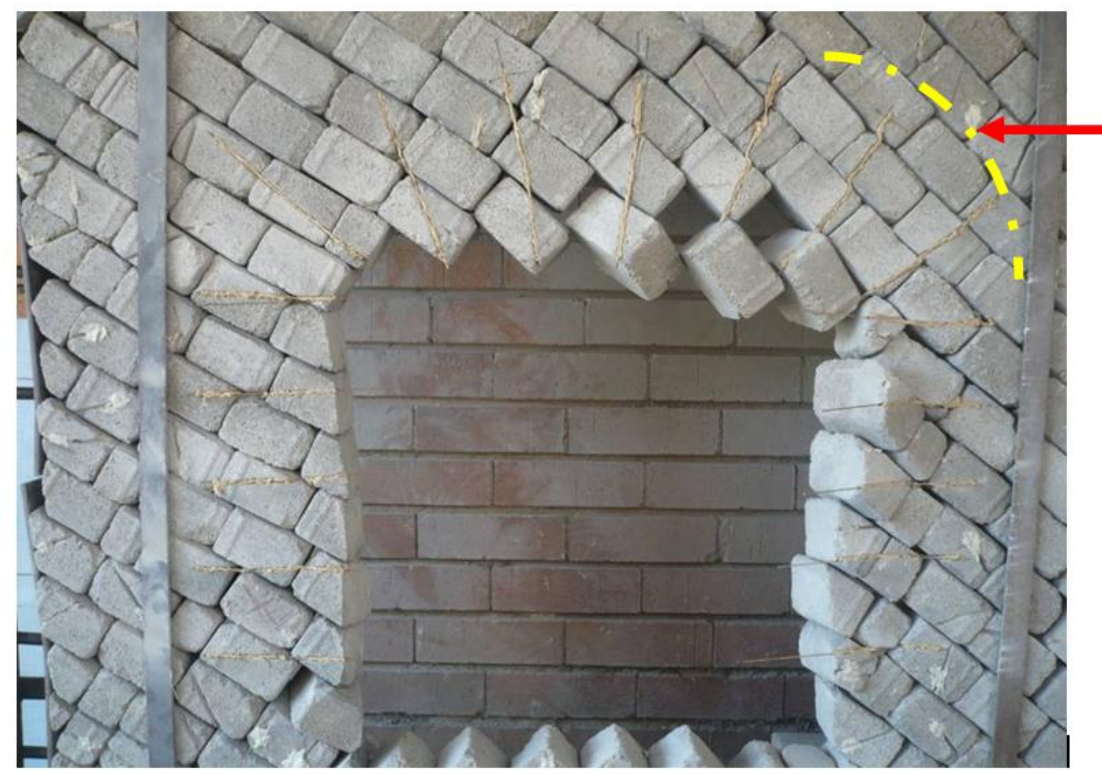

Shear loaded fully grouted rock bolts

Figure 6 Loading of rockbolts and the propagation of block rotation in the roof

As deformations progressed, there was notable rock mass failure between the installed rockbolts in the roof. This failure of unsupported rock blocks resulted in the creation of loose rock blocks which were suspended by rockbolts. These rockbolts were anchored to the competent part of the rock mass structure, which was composed of interlocked rock blocks.

At higher applied deformations, cracking of rock blocks was noted in all the models tested, as illustrated in Figure 7. This occurred when the rock blocks were loaded until they became interlocked, thus restricting any further free movement. This block cracking was mostly gradual, although, on occasion, a violent 'burst' was generated. However, even at this stage the rockbolts were still able to provide structural support, by tying the failing rock blocks to the competent unfailed rock mass strata. The results from this group of models showed very clearly the beneficial effects of rockbolts in maintaining the coherence of the failed rock mass.

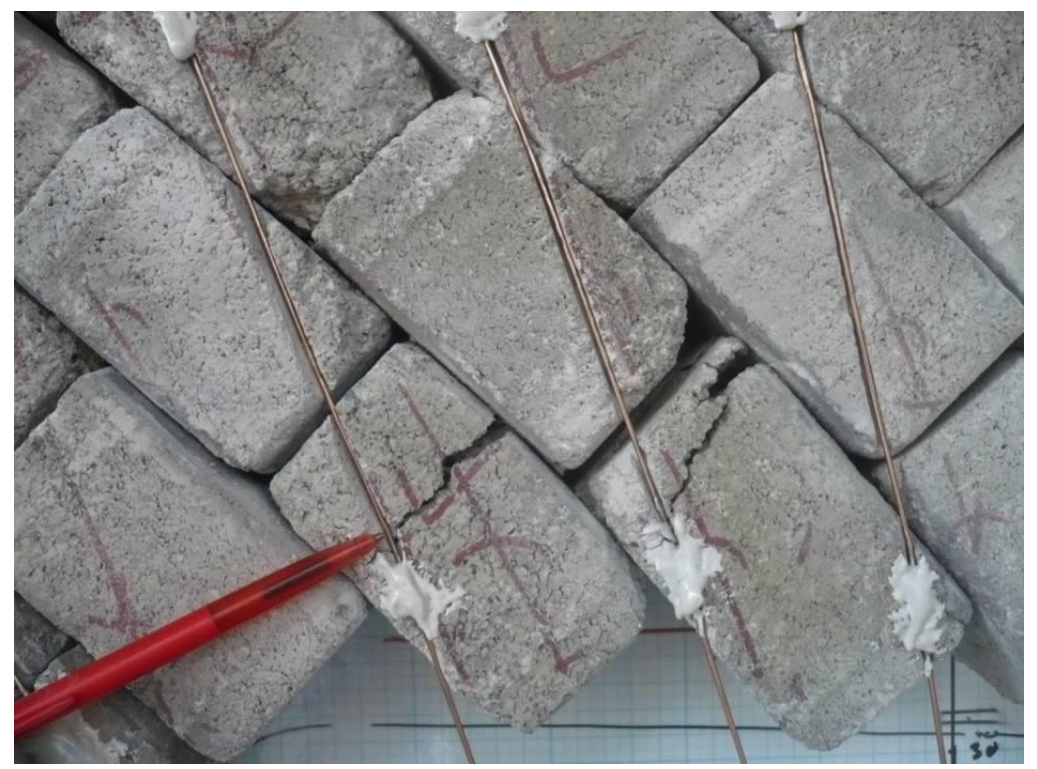

Figure 7 Rock block cracking 


\subsection{3 $45^{\circ}$ orientation}

Models with a $45^{\circ}$ orientation to the horizontal were observed to fail at the tunnel corners as soon as the tunnel perimeter frame was removed. It was also noted that sidewall rock blocks would slide into the tunnel cavity due to gravity loading, as could logically be expected. However, the rock blocks within the roof remained relatively intact.

With increasing applied deformations, rockbolts started failing at their anchorage points. They were pulled out of their grooves as the roof moved down. Loose rock blocks that detached from the rock mass were suspended by rockbolts as shown in Figure 8. This type of behaviour is commonly observed in real underground excavations, as shown in Figure 9.

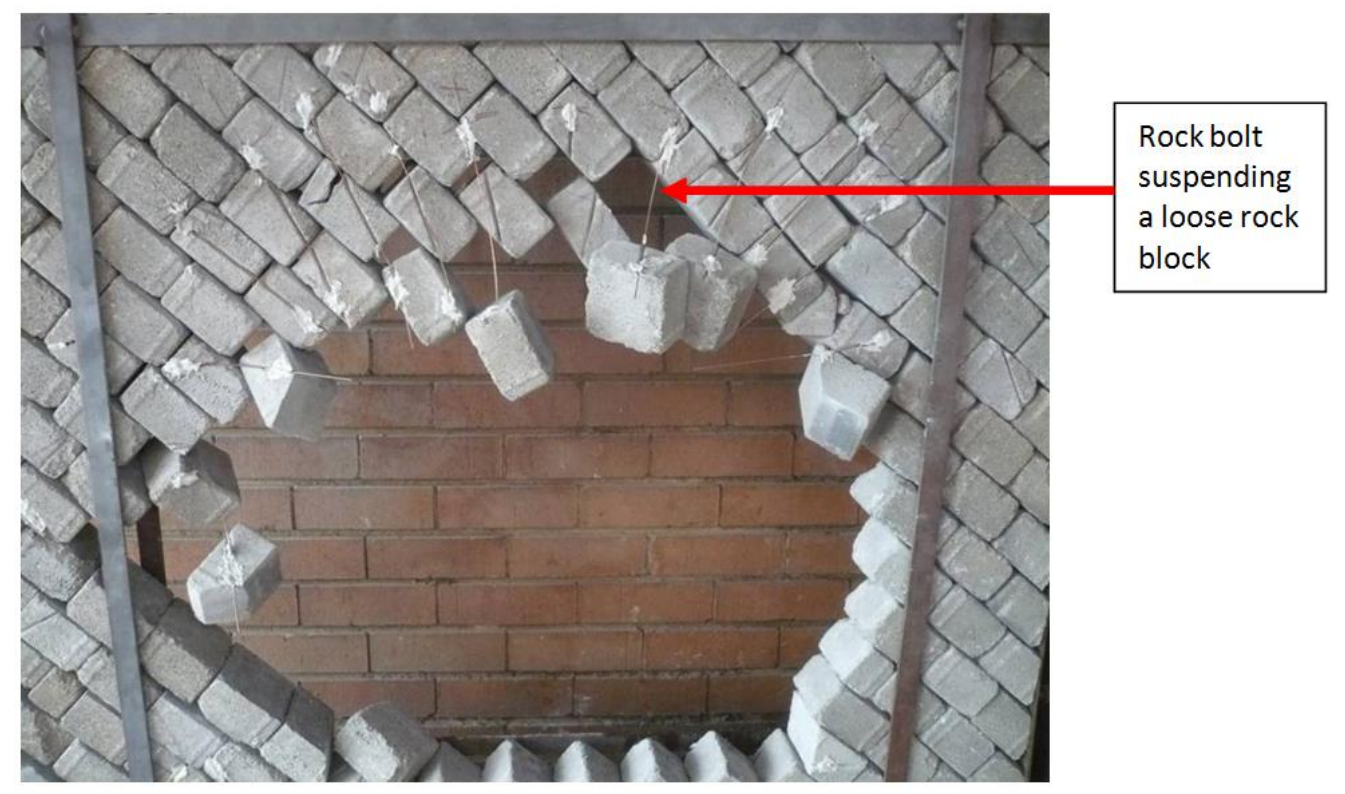

Figure 8 Rockbolt suspension mechanism

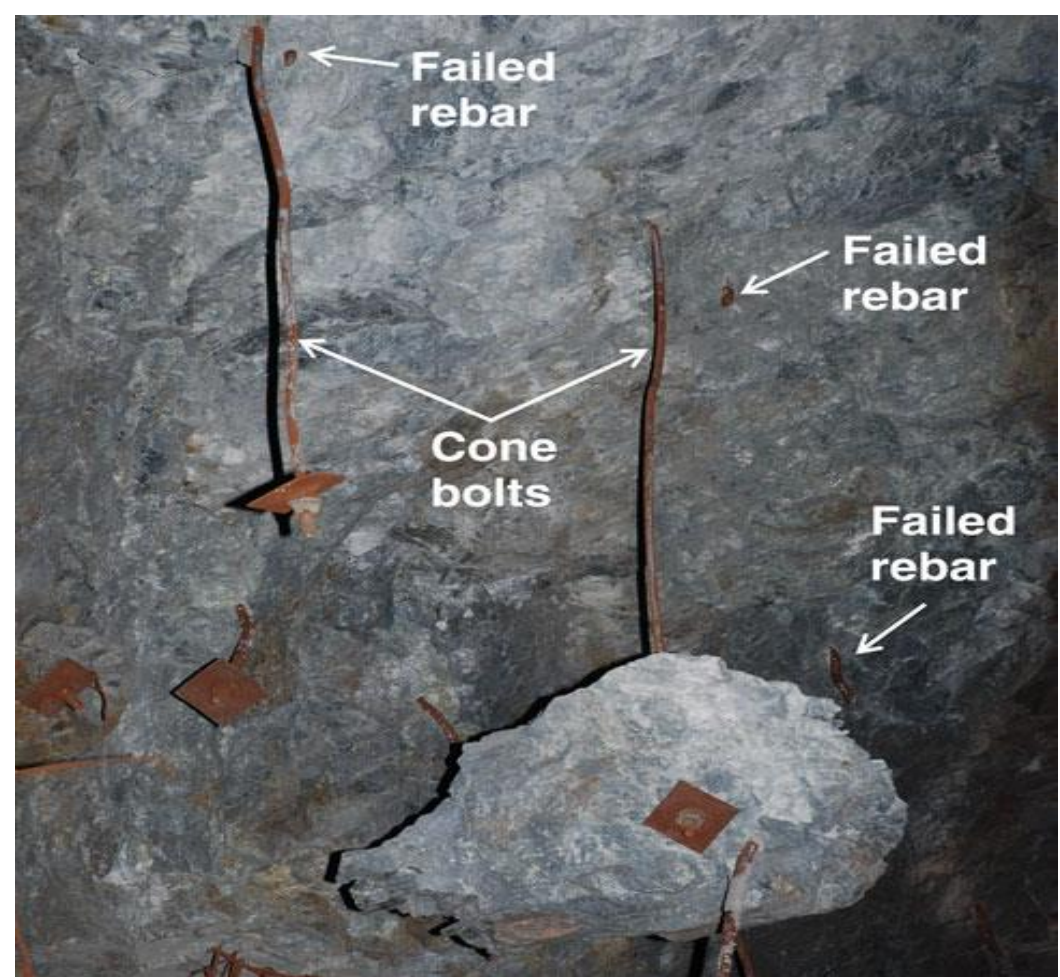

Figure 9 Rockbolts after a rockfall (Li, 2010) 
At higher applied deformations rock blocks began to lock up. This was noted mainly above the failed zone in the roof. Further loading of already interlocked rock blocks resulted in their cracking, as was the case for all the structural orientations. Figure 10 and Figure 7 illustrate this.

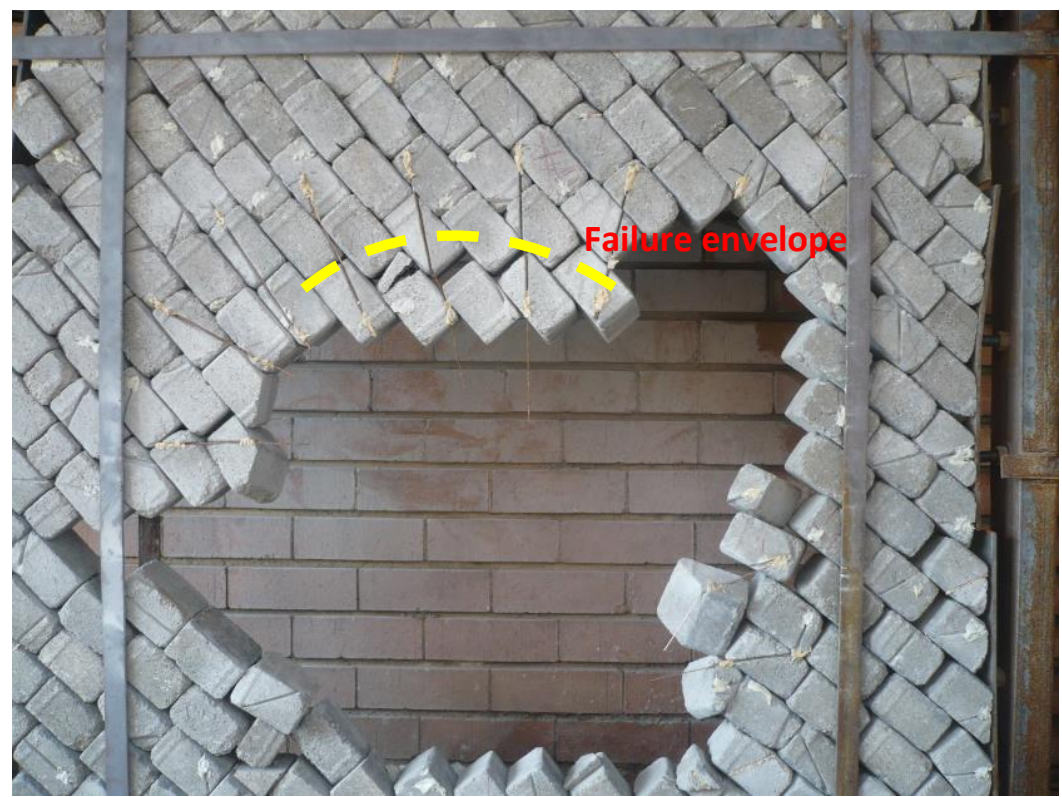

Figure 10 Interlocked blocks above the failure zone

\subsection{4 $60^{\circ}$ oriented structures}

In $60^{\circ}$ oriented structures, the roof was observed to remain intact under gravitational loading, after the tunnel perimeter frame was removed. Block rotation was, however, noted in the upper layers of the roof as illustrated in Figure 10. This rotation resulted in the opening up of cross joints as well as the bending of rockbolts. Initial structural failure was observed in the left sidewall, due to sliding down of rock blocks along the bedding joint set. This phenomenon can be attributed to the orientation of the rock blocks, which makes them more prone to gravitational instability compared to the blocks on the right hand side of the tunnel (see dotted arrows in Figure 11).

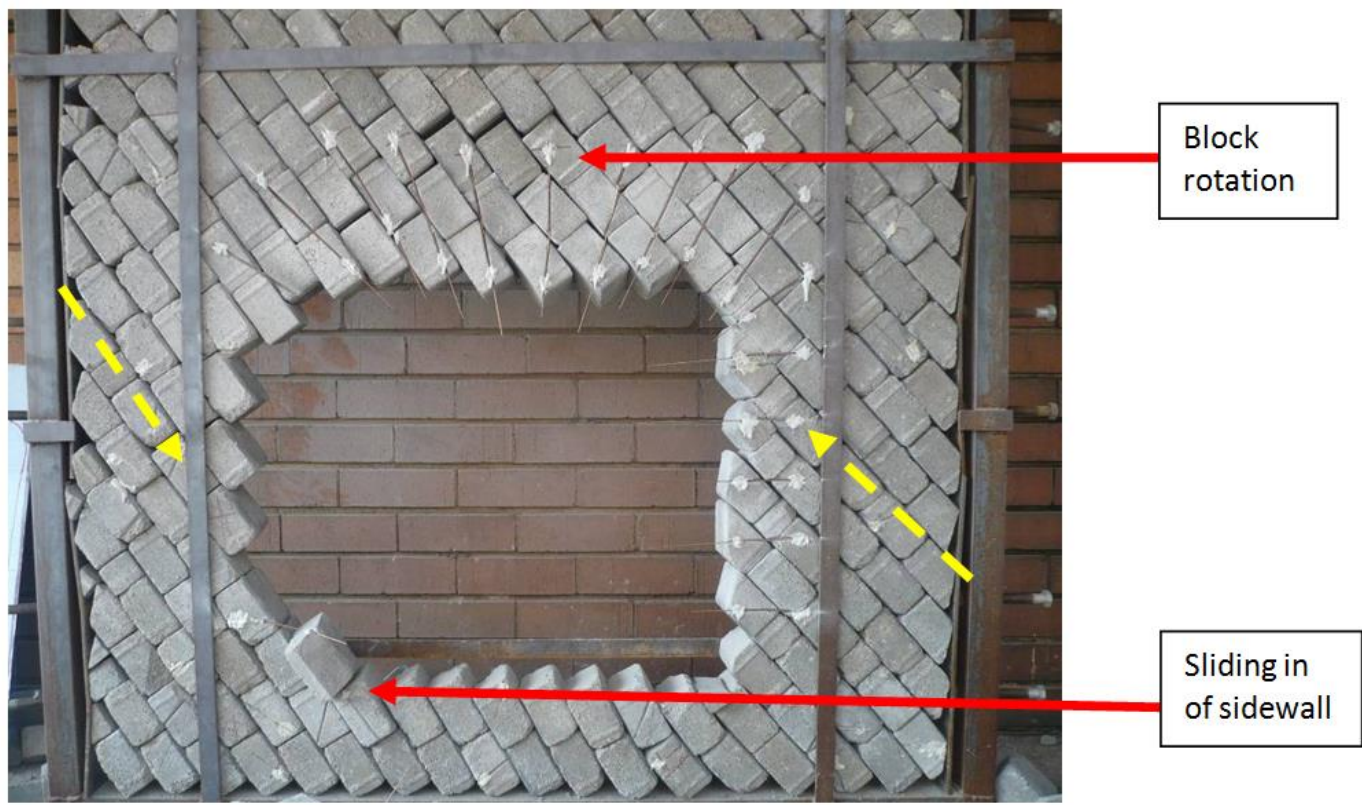

Figure 11 Loaded test model, after the removal of the tunnel frame, and direction of shear movement due to gravity 
When loading commenced, rockbolts at the tunnel shoulders were observed to be under a combination of axial, shear and bending loading, whereas bolts at the centre of the tunnel roof were mainly axially loaded. Rockbolts were also observed to fail at their anchorage points with increasing loads. Anchorage failure led to the falling of rock blocks from the roof, with rockbolts still attached to them. This type of failure behaviour can also be observed in situ as illustrated in Figure 9.

\subsection{Behaviour of rockbolts}

Throughout the tests for different structural orientations, it was observed that rockbolts were subjected to similar loading combinations. From observations of rockbolt deformation, it is possible to suggest that the failure modes respond to complex mechanisms which involve shear, tension and torsion in multiple locations.

Reinforcement schemes were observed to operate only when there was rock mass movement due to loading. This therefore means that the modes of displacement at a discontinuity defined the mode of action of the reinforcing element across that particular discontinuity, which agrees with Windsor and Thompson (1993). Bolted joints were observed to undergo the opening up of joints in a direction perpendicular to the plane, or shear displacement occurring in the plane, or a combination of the two. These movements loaded the rockbolts, in a combination of loading mechanisms, as shown in the models.

\subsubsection{Rockbolt tensile and axial loading}

Rockbolts were observed to suspend loose rock blocks detached from the rock mass by pinning them to the upper competent part of the rock mass structure, as illustrated in Figure 6. This upper part of the rock mass structure was self-supporting, and the rockbolts were observed to support the failed rock blocks, and, under these suspension conditions, axial loads were generated in the rockbolts. It was also observed that the reaction of the rock and/or grout, to the rockbolt deflection, resulted in the loading of the bolts axially.

\subsubsection{Rockbolt shear loading}

Rockbolts were observed to be subjected to shear loading as a result of beam bending and slip along joints. It was also noted that installed rockbolts provided an additional resistance against shear failure along joints and weakness planes. Figure 12 and 13 below, illustrate this rockbolt behaviour. Rockbolts also provide shear and/or frictional strength across discontinuities (U.S. Army Corps of Engineers, 1997).

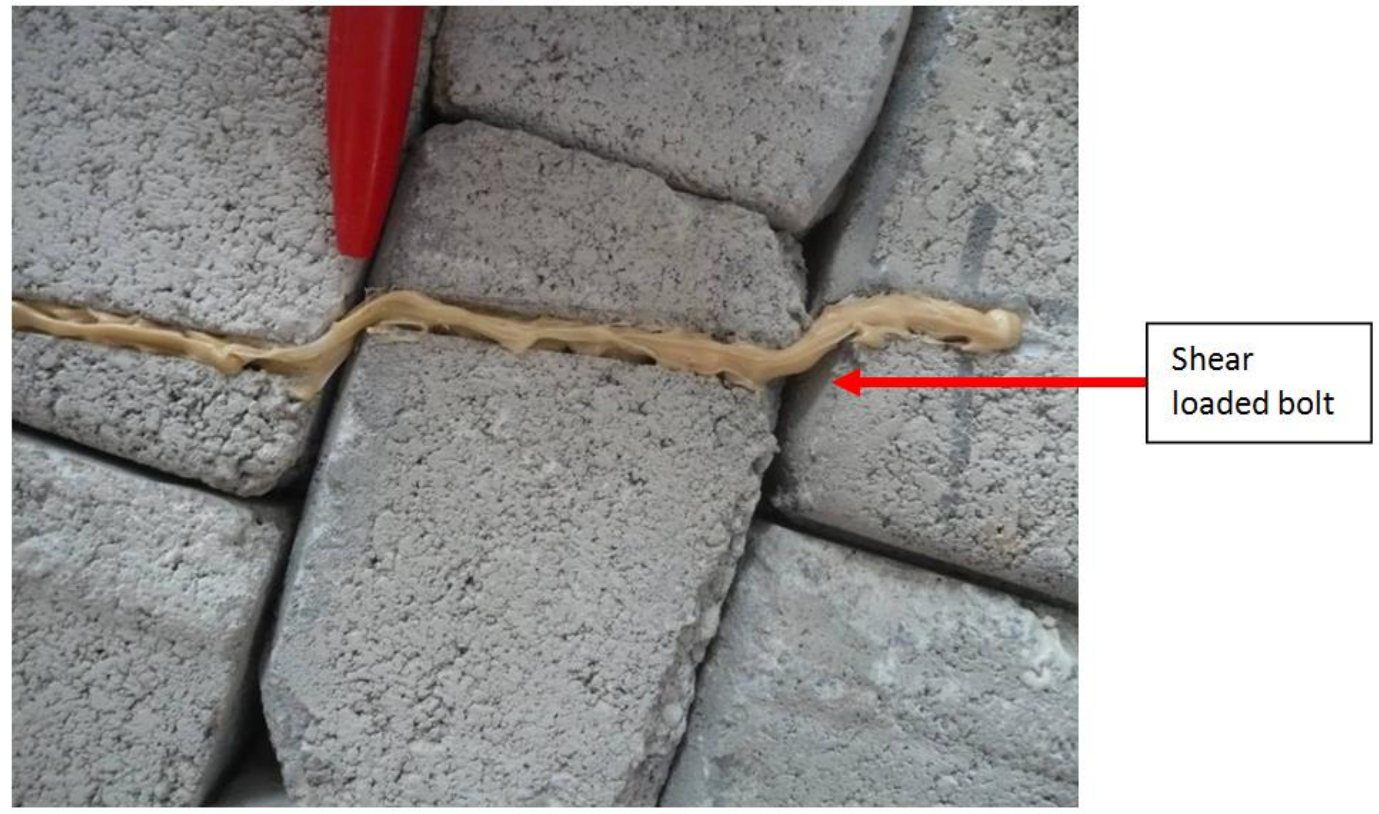

Figure 12 Rockbolt traversing joints 


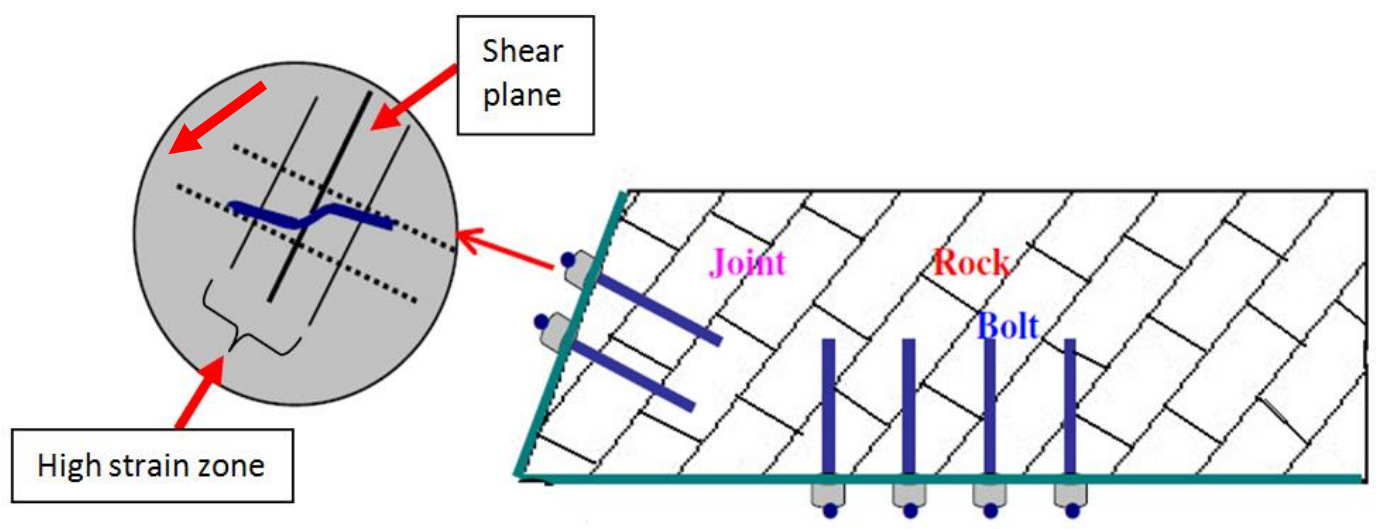

Figure 13 Grouted rockbolts traversing rock joints (after Jalalifar et al., 2006)

The installed rockbolts portrayed ductile failure characteristics. When load was applied they stretched or sheared, as is the case with soft rock support. According to Van der Merwe and Madden (2002), rockbolts can be classified as a flexible support system.

\subsubsection{Rockbolt bending loading}

This rockbolt mechanism was observed in cases where movement took place along joints, thus it was observed in combination with shear loading, as shown in Figure 14. When a bolted joint was subjected to shearing, the amount of bending that it experienced was directly proportional to the load applied. In the majority of cases the shear load on the rockbolt was greater with increasing deformation of the rock mass. This means that as the amount of bending increased, so did the rockbolt curvature. In accordance with Spang and Egger (1990), the deformed shape of the rockbolts showed two singular points: one in the rockbolt-joint intersection and another at the point of maximum bending moment (hinge point). However, rockbolts remained intact and effective up to the maximum deformation that could be generated by the boundary deformation process.

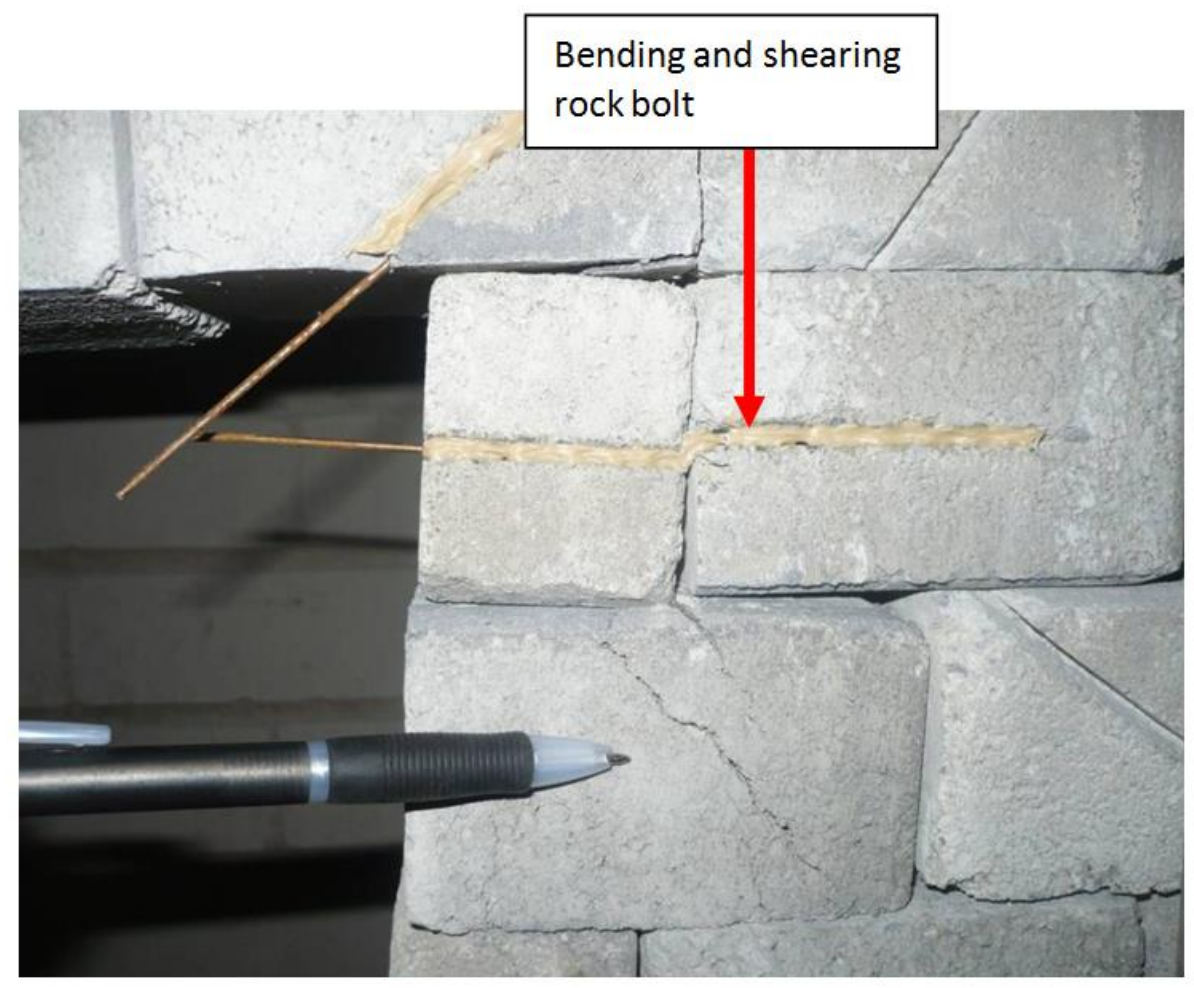

Figure 14 Combination of bending and shear bolt loading 


\section{$4 \quad$ Conclusions}

The following conclusions can be drawn from the research project:

- Physical modelling still has value in our computerised world, as it allows the simple demonstration of the effectiveness of rockbolt behaviour which is not always evident in other modelling techniques.

- In highly jointed rock masses where there is significant movement across the joints, rockbolts with good ductility and deformation qualities will be of benefit since they will permit joint movement and rock fracturing without failing. This is especially important, since rockbolts are not able to prevent stress-induced fracturing and yielding. They should therefore, be able to maintain the geometric integrity of the rock mass, allowing stresses to redistribute and to assist the fractured rock mass itself to provide the required support. The models demonstrated this mechanism very clearly.

- For effective support in jointed rock structures, rock movement should be inhibited from the outset, in order to counter rock rotation. Rockbolts have continuously proven ineffective in arresting this block rotation, hence the need for additional support which has the ability to inhibit the rotation of rock blocks by penetrating through joints and promoting interlocking of block. Shotcrete or thin spray-on liners can contribute in this regard by penetrating into joints and cracks, thus inhibiting rock block movement (Stacey, 2001).

- The interaction between rockbolts and the jointed rock mass is a critical factor when it comes to supporting jointed rock masses. This is in contrast with the concept that, in a discontinuous rock mass environment, there is limited interaction between the rockbolt reinforcement and the rock mass at the boundary of the excavation. Plates and mesh/screen will contribute further to such interaction.

- The stability of the rock mass between rockbolts is a function of the spacing of the rockbolts. The higher the reinforcement density, the more stable the rock mass between the rockbolts, and consequently the greater the overall tunnel stability.

- The reinforcement mechanism of rockbolts is dictated by the behaviour and movement of the rock mass in which they are installed. Rockbolts also play an important part in holding jointed rock masses intact, and also in the prevention of key block failure.

- The reinforcement capacity of a rockbolt support system increases with reinforcement length. Length is especially critical for rockbolts at the tunnel shoulders. Longer rockbolts are also very useful in controlling roof sag, particularly in horizontally jointed rock masses, and also beneficial in maintaining sidewall integrity.

The models indicate, particularly, the importance of bolts being able to yield in shear and tension without failure where they cross joints, if rock mass failure is to be inhibited and deformation contained. Even though the investigation made use of simple, demonstrative models rather than similitude models, many mechanisms of rockbolt and rock mass behaviour that are observed in situ were illustrated. The simple physical modelling is therefore considered to have provided good research value.

\section{Acknowledgements}

The authors would like to express their thanks to the University of the Witwatersrand School of Mining Engineering, and to the South African National Research Foundation (NRF) for funding received.

\section{References}

Barley, A.D. and Windsor, C.R. (2000) Recent advances in ground anchor and reinforcement technology with reference to the development of the art, in Proceedings GeoEng 2000 International Conference, November 19-21, Melbourne, Australia. 
Barton, N., Lien, R. and Lunde, J. (1974) Engineering classification of rock masses for the design of tunnel support, International Journal of Rock Mechanics and Mining Sciences and Geomechanics Abstracts, Vol. 6, No. 4, pp. 189-236.

Barton, N. (2002) Some new Q-value correlations to assist in site characterization and tunnel design, International Journal of Rock Mechanics and Mining Sciences and Geomechanics Abstracts, Vol. 39, pp. 185-216.

Cording, E.J., Hendron, A.J. and Deere, D.U. (1971) Rock Engineering for underground caverns, in Proceedings of the Symposium on Underground Rock Chambers, New York, American Society of Civil Engineers, pp. 567-600.

Farmer, I.W. and Shelton, P.D. (1980) Factors that affect underground rock bolt reinforcement systems, Transactions of the Institution of Mining and Metallurgy, Vol. 89, pp. 68-83.

Grasselli, G. (2004) 3D Behaviour of bolted rock joints: experimental and numerical study, International Journal of Rock Mechanics and Mining Sciences, Vol. 42, pp. 13-24.

Hoek, E., Kaiser, P.K. and Bawden, W.F. (2000) Support of underground excavations in hard rock, Balkema, Rotterdam, Brookfield, pp. 99-155.

Jalalifar, H., Aziz, N.I. and Hadi, M. (2006) An assessment of load transfer mechanism using the instrumented bolts, in Proceedings Coal 2006: Coal Operators' Conference, N. Aziz (ed), Coal 2006: Coal Operators' Conference, 6-7 July, University of Wollongong and the Australasian Institute of Mining and Metallurgy, 2006, pp. 255-265.

Li, C.C. (2010) Field observations of rock bolts in high stress rock masses, Rock Mechanics and Rock Engineering, Vol. 43, pp. 491-496.

Mark, C., Molinda, G.M. and Dolinar, D.R. (2001) Analysis of roof bolt systems, in Proceedings 20th International Conference on Ground Control in Mining, Morgantown, West Virginia University, August, 2001, pp. 218-225.

Peng, S.S. and Tang, D.H.Y. (1984) Roof bolting in underground mining: a state-of-the-art review, International Journal of Mining Engineering, Vol. 2, 1984, pp. 1-42.

Sakurai, S. (2008) Modelling strategy for jointed rock masses reinforced by rock bolts in tunnelling practice, Acta Geotechnica, Vol. 5, pp. 121-126.

Spang, K. and Egger, P. (1990) Action of Fully-Grouted Bolts in Jointed Rock and Factors of Influence, Rock Mechanics and Rock Engineering, Vol. 23, 1990, pp. 201-229.

Stacey, T.R. (2001) Review of membrane support mechanisms, loading mechanisms, desired membrane performance, and appropriate test methods, The Journal of the South African Institute of Mining and Metallurgy, pp. 343-352.

U.S. Army Corps of Engineers (1997) Engineering and design; Tunnels and shafts in rock, U.S. Army Corps of Engineers, Manual No. 1110-2-2901, p. 236.

Van der Merwe, J.N. and Madden, B.J. (2002) Rock Engineering for Underground Coal Mining, A Practical Guide for Supervisors at all levels, Mine Planners and Students, Safety in Mines Research Advisory Committee (SIMRAC), The South African Institute of Mining and Metallurgy Special Publications, Series 7 (SP7), pp. 50-52 and p. 201.

Windsor, C.R. and Thompson, A.G. (1993) Rock Reinforcement - Technology, Testing, Design and Evaluation, Comprehensive Rock Engineering, Principles, Practice and Projects, J. Hudson (ed), Pergamon Press, Oxford, Vol. 4, 1993, pp. 451-484. 
